\title{
Game Theory Analysis of the Pricing of Foreign Trade Products in High Tech Industry
}

\author{
Jianna Zhao \\ Department of Economics and Management \\ North China Electric Power University, China \\ No.689 Huadian Road, Beishi district, Baoding, 071003, \\ China \\ zhjnzhf@163.com
}

\author{
Tongfei Zhao \\ Department of Economics and Management \\ North China Electric Power University, China \\ No.689 Huadian Road, Beishi district, Baoding, 071003, \\ China \\ ztfde93314@163.com
}

\begin{abstract}
High tech industry as the embodiment of the comprehensive strength in different countries has become the main force of international competition. In this paper, the Hotelling model is used to analyze the problem of pricing the products. We find out that equal pricing will bring them greatest profits when maximizing the differentiation of products and same level protection. Resolution is that countries are necessary to cooperated in an organization of high tech industries. To get agreement on pricing, and eliminate disputes and avoid the result of both lose. And there should be a mature international legal system and a steady circumstance.
\end{abstract}

Keywords—high tech industry; trade protection; game theory

\section{INTRODUCTION}

With the development of globalization and the integration of world economy, the competition in each country is more and more intense. And the high tech has become one of the elements of contemporary advanced productive forces. High tech industry is a high degree of talent, knowledge, technology and capital intensive. It includes pharmaceutical manufacturing, aerospace manufacturing, electronic communications and equipment manufacturing, electronic computer and office equipment manufacturing, pharmaceutical equipment and instrumentation manufacturing [1]

As the strategic leading industry of the national economy, the high tech industry affects the adjustment of industrial structure and the transformation of economic development mode. Therefore many countries have put the development of the high technology industry as the focus of international trade competition $^{[2]}$. In the game of foreign trade of high tech industry, countries especially developed countries, take different measures to enhance the competitiveness of high tech products in order to maximize the benefits. But how to price the high tech products has become a key issue for the development of high tech industries.

\section{THE DEVELOPMENT OF HIGH TECH INDUSTRY}

Since 1990s, the foreign trade of high tech industry has become an important force to promote the rapid development of international trade. From the current situation in the foreign trade of high tech industry, the developed countries have occupied $80 \%$ of export trade in high tech industry. Although the strengths of high tech industry in emerging industrial countries and some developing countries are not strong, under the support of the national governments, in recent years, the pace of foreign trade has accelerated.

Since the implementation of "Science and Technology" in China, the import and export in high tech industry has made considerable progress. In 2007, China's exports of high tech products accounted for $18.1 \%$ of the world market, for the first time to become the world's first exporter ${ }^{[3]}$. The high tech industries are mainly concentrated in the eastern region of China, but the development of the western region's high tech industries is relatively backward. It is significant to enhance the structural layout of China's high tech industries, and effectively guide the industrial agglomeration.

The trade surplus of high tech industry reflects that the Chinese high tech products have a certain export advantage in the international market, and the contribution to economic growth is also growing. Compared with the United States and other developed countries, in the export of computer communications technology, China's high tech industries are significantly higher. All of these show the structural imbalance, and there may be some trade risks in China's high tech industries. According to the relevant data of the World Bank, we can get the top ten countries in the world in 2013.

TABLE I. TOP RANKINGS

\begin{tabular}{|c|c|c|c|}
\hline Country & $\begin{array}{c}\text { Export Volume } \\
\text { (Billion) }\end{array}$ & $\begin{array}{c}\text { Proportion } \\
\mathbf{( \% )}\end{array}$ & $\begin{array}{c}\text { Speed } \\
\mathbf{( \% )}\end{array}$ \\
\hline China & 5600.58 & 27.80 & 10.76 \\
\hline Germany & 1930.88 & 9.58 & 5.31 \\
\hline America & 1478.33 & 7.34 & -0.63 \\
\hline Singapore & 1356.02 & 6.73 & 5.74 \\
\hline Korea & 1304.60 & 6.48 & 7.54 \\
\hline France & 1130.00 & 5.61 & 4.28 \\
\hline Japan & 1050.76 & 5.22 & -14.86 \\
\hline Netherlands & 690.40 & 3.43 & 7.94 \\
\hline Malaysia & 603.72 & 3.00 & -1.40 \\
\hline Switzerland & 533.50 & 2.65 & 6.48 \\
\hline
\end{tabular}

In a certain extent, the export volume of a national industry and the proportion of its total exports in the world can directly 
reflect the strength of the international competitiveness of the country's industry ${ }^{[4]}$. It is not difficult to see that high tech industry exports in China take up a large slice of the world market, and the growth rate as high as $10.76 \%$. In the traditional developed countries, Japan's negative growth in the traditional developed countries reaches $14.86 \%$, the world's total exports ranks only seventh, and the United States also appears negative growth. But in this case, China's high tech industry still maintained a high growth momentum.

\section{PRICING GAME OF HIGH TECH PRODUCTS}

High tech industry foreign trade game, in fact, is the game between different oligopolies on output and product price ${ }^{[5]}$. In this paper, we use the Hotelling model, and introduce the product differentiation to analysis the game of high tech industry trade pricing. In the Hotelling model, if the product position is different, the equilibrium price of the product is no longer equal to the marginal cost ${ }^{[6]}$. Therefore, enterprises should not only consider the value of the product selection, but also consider the choice of product prices.

\section{A. Model Hypothesis}

First of all, it is assumed that the pricing game is a bilateral trade pricing game, that is, the game is between the two countries in the high tech industries. Second, each of game countries only has one high tech enterprise in all areas of high technology industry. Last, the two countries' high tech enterprises are free trade in the international market, and the governments have not taken any trade subsidy policies.

Assuming that there are two different countries A and B, respectively, they have high tech enterprises for 1 and 2 . The product bit value is interval $[0,1]\left(a_{1}\right.$ and $\left.a_{2}, a_{2}>a_{1}\right)$. The consumer's preference $h$ for the product is subject to the uniform distribution on the $[0,1]$. When consumers choose to $a_{1}$, the deviation cost they need to pay is the $t\left(h-a_{1}\right)^{2}$. When consumers choose to $a_{2}$, the deviation cost they need to pay is the $t\left(h-a_{2}\right)^{2}$. In order to ensure the deviation cost is positive, we have to take the square.

Consumers have the unit demands for the high tech products. They should pay for the cost of two parts, namely, the price cost and the deviation cost. When consumer preference is assumed $h=h^{*}$, there is no difference between the two values of the products, and we have $P_{1}+t\left(h^{*}-a_{1}\right)^{2}=P_{2}+t\left(h^{*}-a_{2}\right)^{2}$. If $\bar{a}=\frac{a_{1}+a_{2}}{2}$ and $\square a=a_{2}-a_{1}$, we have $h^{*}=\bar{a}+\frac{1}{2 t \square a}\left(P_{2}-P_{1}\right)$.

If there is only one typical consumer in the market, the demand for the product with the value of $a_{1}$ is $X_{1}\left(a_{1}, a_{2}, P_{2}, P_{1}\right)=\bar{a}+\frac{1}{2 t \square a}\left(P_{2}-P_{1}\right) \cdot \bar{a}$ is the natural source for enterprise1. It indicates the market demand for the product of the enterprise 1 when the prices of the two products are the same. $\frac{1}{2 t \square a}$ is the market competitive strength. $P_{2}-P_{1}$ is the price advantage of enterprise1. The greater the intensity of competition, the greater the impact of price advantage on demand.

Using to represent the demand function of enterprise2, we can get the relation.

$$
\begin{aligned}
X_{2}\left(a_{1}, a_{2}, P_{2}, P_{1}\right) & =1-X_{1}\left(a_{1}, a_{2}, P_{2}, P_{1}\right) \\
& =1-\bar{a}+\frac{1}{2 t \square a}\left(P_{1}-P_{2}\right)
\end{aligned}
$$

Therefore, the profit functions of the two enterprises can be getting.

$$
\begin{gathered}
\pi_{1}\left(a_{1}, a_{2}, P_{2}, P_{1}\right)=\left(P_{1}-c\right)\left(\bar{a}+\frac{P_{2}-P_{1}}{2 t \square a}\right) \\
\pi_{2}\left(a_{1}, a_{2}, P_{2}, P_{1}\right)=\left(P_{2}-c\right)\left(1-\bar{a}+\frac{P_{1}-P_{2}}{2 t \square a}\right)
\end{gathered}
$$

The model is divided into two stages. The first stage is the two companies choose the value of $a_{1}$ and $a_{2}$ at the same time. The second stage is the price competition of two enterprises.

\section{B. Model Solution}

We will use the reverse push method to solve the model's subgame perfect Nash equilibrium. In the second stage, two enterprises have informed the value, and chose the price to make their own profit function to reach the maximum.

For enterprise1, $a_{1}, a_{2}$ and $P_{2}$ are fixed. Then, we solve the maximization problem of $P_{1}$.

$$
\max _{P_{1}} \pi_{1}\left(a_{1}, a_{2}, P_{2}, P_{1}\right)=\left(P_{1}-c\right)\left(\bar{a}+\frac{P_{2}-P_{1}}{2 t \square a}\right)
$$

The first order derivative method is used to solve the formula. We can get the price response function of the enterprise 1 about 2 .

$$
P_{1}=\frac{1}{2}\left(P_{2}+c+2 t \bar{a} \square a\right)
$$

For enterprise2, $a_{1}, a_{2}$ and $P_{1}$ are fixed. Then, we solve the maximization problem of $P_{2}$.

$$
\max _{P_{2}} \pi_{2}\left(a_{1}, a_{2}, P_{2}, P_{1}\right)=\left(P_{2}-c\right)\left(1-\bar{a}+\frac{P_{1}-P_{2}}{2 t \square a}\right)
$$

The first order derivative method is used to solve the formula. We can get the price response function of the enterprise 2 about 1 .

$$
P_{2}=\frac{1}{2}\left[P_{1}+c+2 t(1-\bar{a}) \square a\right]
$$

The intersection of (2) and (4) in the two reaction curves is the subgame perfect Nash equilibrium, which is based on $\left(a_{1}, a_{2}\right)$, and becomes the Bertrand-Nash equilibrium. 


$$
P_{1}^{B}\left(a_{1}, a_{2}\right)=c+\frac{2}{3} t(1+\bar{a}) \square a \quad P_{2}^{B}\left(a_{1}, a_{2}\right)=c+\frac{2}{3} t(2-\bar{a}) \square a
$$

$X_{1}^{B}\left(a_{1}, a_{2}\right)=\bar{a}+\frac{1}{2 t \square a}\left(P_{2}-P_{1}\right)=\frac{1+\bar{a}}{3} \quad X_{2}^{B}\left(a_{1}, a_{2}\right)=1-\bar{a}+\frac{1}{2 t \square a}\left(P_{1}-P_{2}\right)=\frac{2-\bar{a}}{3}$

After substituting the equilibrium price and output into the corporate profit function, we can get the price profit functions.

$$
\pi_{1}^{B}\left(a_{1}, a_{2}\right)=\frac{2}{9} t(1+\bar{a})^{2} \square a \quad \pi_{2}^{B}\left(a_{1}, a_{2}\right)=\frac{2}{9} t(2-\bar{a})^{2} \square a
$$

If $\square a=0$, we have $P_{1}=P_{2}=c$. In the first stage, two enterprises can select the bit value at the same time to maximize their reduced order profit function.

For enterprise1, solving the maximization problem of $a_{1}$.

$$
\max _{a_{1}} \pi_{1}^{B}\left(a_{1}, a_{2}\right)=\frac{2}{9} t(1+\bar{a})^{2} \square a
$$

The first order derivative method is used to solve the formula.

$$
\frac{\partial \pi_{1}^{B}\left(a_{1}, a_{2}\right)}{\partial a_{1}}=\frac{2}{9} t(1-\bar{a}) \frac{a_{2}-3 a_{1}-2}{2}<0
$$

Because $a_{1} \in[0,1]$, so when $a_{1}=0$ and $a_{2}=1$,we can get the maximum value.

For enterprise2, solving the maximization problem of $a_{2}$.

$$
\max _{a_{2}} \pi_{2}^{B}\left(a_{1}, a_{2}\right)=\frac{2}{9} t(2-\bar{a})^{2} \square a
$$

The first order derivative method is used to solve the formula.

$$
\frac{\partial \pi_{1}^{B}\left(a_{1}, a_{2}\right)}{\partial a_{1}}=\frac{2}{9} t(1-\bar{a}) \frac{a_{2}-3 a_{1}-2}{2}<0
$$

Because $a_{2} \in[0,1]$, so when $a_{2}=1$,we can get the maximum value.

Therefore, the two enterprises make their products difference in equilibrium. When $a_{1}=0$ and $a_{2}=1$, we have $P_{1}^{*}=P_{2}^{*}=c+t, X_{1}^{*}=X_{2}^{*}=\frac{1}{2}, \pi_{1}^{*}=\pi_{2}^{*}=\frac{t}{2}$.

\section{PRICING GAME WITH DIFFERENT CONSIDERATION FACTORS}

The above model assumes that the cost is the same. But in real life, different companies have different cost of innovation and intellectual property protection of their products, so the final performance of the cost of the product will be different ${ }^{[7]}$.

\section{A. Model Hypothesis}

Assuming that there are two different countries A and B, respectively, they have high tech enterprises for 1 and 2 . The product bit value is interval $[0,1]$. We are working on the assumption that enterprise 1 is located at $a_{1}=0$ and enterprise 2 is located at $a_{2}=1$. When consumers choose to $a_{1}$, the deviation cost they need to pay is the $t(h-0)$. When consumers choose to $a_{2}$, the deviation cost they need to pay is the $t(1-h)$. Because there is problem of positive and negative numbers, so we do not take the square.

If such a situation occurs like $P_{1}^{*}+t(h-0)=P_{2}^{*}+t(1-h)$, there's no different to consume two kinds of products. And we will get $h=\frac{1}{2}\left(1+\frac{P_{2}^{*}-P_{1}^{*}}{t}\right)$. Among them, $P_{1}^{*}$ and $P_{2}^{*}$ indicate the equilibrium prices for the market.

If there is only one typical importer in the market, the demand for the product is $P_{1}^{*}+t(h-0)=P_{2}^{*}+t(1-h)$. The requirement for enterprise 1 can be get.

$$
X_{1}\left(P_{1}, P_{2}\right)=\frac{1}{2}\left(1+\frac{P_{2}^{*}-P_{1}^{*}}{t}\right)
$$

Using $X_{2}\left(P_{1}, P_{2}\right)$ to represent the demand function of enterprise2, we can get the requirement for enterprise2.

$$
X_{2}\left(P_{1}, P_{2}\right)=\frac{1}{2}\left(1+\frac{P_{1}^{*}-P_{2}^{*}}{t}\right)
$$

Therefore, the profit functions of the two enterprises are $\pi_{1}=\left(P_{1}^{*}-C_{1}\right) X_{1}$ and $\pi_{2}=\left(P_{2}^{*}-C_{2}\right) X_{2}$. Among them, $C_{1}$ and $C_{2}$ indicate the product costs of enterprise1 and enterprise2.And we get $c_{1}=\beta k_{1}^{2}+c_{0}, c_{2}=\beta k_{2}^{2}+c_{0}$.

$k_{1}$ and $k_{2}$ indicate the protections of intellectual property rights of enterprise 1 and enterprise2, and $0<k<1$. The greater the protection of the company's products, the higher the degree. $\beta$ is the influence factor of intellectual property right protection on innovation cost. $C_{0}$ is the fixed cost that not affected by of protection.

The model is divided into two stages. The first stage is the two enterprises to select the degree of protection of intellectual property rights. The second stage is the price competition of two enterprises.

\section{B. Model Solution}

We will use the reverse push method to solve the model's subgame perfect Nash equilibrium. In the second stage, the two enterprises have learned the investments level of R \& D costs from each other. At the same time, they select the prices $\left(P_{1}, P_{2}\right)$ that can make their profit functions to achieve maximum.

For enterprise1, $k_{1}, k_{2}$ and $P_{2}$ are fixed. Then, we solve the maximization problem of $P_{1}$.

$$
\begin{aligned}
\max _{P_{1}} \pi_{1}\left(k_{1}, k_{2}, P_{1}, P_{2}\right) & =\left(P_{1}-c_{1}\right) X_{1} \\
& =\frac{1}{2}\left(P_{1}-\beta k_{1}^{2}-c_{0}\right)\left(1+\frac{P_{2}-P_{1}}{2 t}\right)
\end{aligned}
$$

The first order derivative method is used to solve the formula. 


$$
P_{1}=\frac{1}{2}\left(P_{2}+t+\beta k_{1}^{2}+c_{0}\right)
$$

For enterprise $1, k_{1}, k_{2}$ and $P_{1}$ are fixed. Then, we solve the maximization problem of $P_{2}$.

$$
\begin{aligned}
\max _{P_{2}} \pi_{2}\left(k_{1}, k_{2}, P_{1}, P_{2}\right) & =\left(P_{2}-c_{2}\right) X_{2} \\
& =\frac{1}{2}\left(P_{2}-\beta k_{2}^{2}-c_{0}\right)\left(1+\frac{P_{1}-P_{2}}{2 t}\right)
\end{aligned}
$$

The first order derivative method is used to solve the formula.

$$
P_{2}=\frac{1}{2}\left(P_{1}+t+\beta k_{2}^{2}+c_{0}\right)
$$

The intersection of (10) and (12) in the two reaction curves is the subgame perfect Nash equilibrium, which is based on $\left(k_{1}, k_{2}\right)$, and becomes the Bertrand-Nash equilibrium.

$$
\begin{array}{ll}
P_{1}^{B}\left(k_{1}, k_{2}\right)=t+c_{0}+\frac{\beta}{3}\left(2 k_{1}^{2}+k_{2}^{2}\right) & P_{2}^{B}\left(k_{1} k_{2}\right)=t+c_{0}+\frac{\beta}{3}\left(k_{1}^{2}+2 k_{2}^{2}\right) \\
X_{1}^{B}\left(k_{1}, k_{2}\right)=\frac{1}{2}\left[1+\frac{\beta}{3 t}\left(k_{2}^{2}-k_{1}^{2}\right)\right] \quad X_{2}^{B}\left(k_{1}, k_{2}\right)=\frac{1}{2}\left[1+\frac{\beta}{3 t}\left(k_{1}^{2}-k_{2}^{2}\right)\right]
\end{array}
$$

After substituting the equilibrium price and output into the corporate profit function, we can get the price profit functions.

$$
\pi_{1}^{B}\left(k_{1}, k_{2}\right)=\frac{t}{2}\left[1+\frac{\beta}{3 t}\left(k_{2}^{2}-k_{1}^{2}\right)\right]^{2} \pi_{2}^{B}\left(k_{1}, k_{2}\right)=\frac{t}{2}\left[1+\frac{\beta}{3 t}\left(k_{1}^{2}-k_{2}^{2}\right)\right]^{2}
$$

If two enterprises have the common protections of intellectual property rights and the investments level of R \& D costs.

$$
P_{1}^{B}\left(k_{1}, k_{2}\right)=P_{2}^{B}\left(k_{1}, k_{2}\right)=t+c_{0}+\beta k^{2}, \quad k_{1}=k_{2}=k
$$

In the first stage, two enterprises can choose the investments in R \& D costs at the same time to maximize their reduced order profit function.

For enterprise1, solving the maximization problem of $k_{1}$.

$$
\max _{k_{1}} \pi_{1}^{B}\left(k_{1}, k_{2}\right)=\frac{t}{2}\left[1+\frac{\beta}{3 t}\left(k_{2}^{2}-k_{1}^{2}\right)\right]^{2}
$$

The first order derivative method is used to solve the formula.

$$
\frac{\partial \pi_{1}^{B}}{\partial k_{1}}=\frac{2 \beta}{3} k_{1}\left[1+\frac{\beta}{3 t}\left(k_{2}^{2}-k_{1}^{2}\right)\right]
$$

For enterprise1, solving the maximization problem of $k_{2}$.

$$
\max _{k_{2}} \pi_{2}^{B}\left(k_{1}, k_{2}\right)=\frac{t}{2}\left[1+\frac{\beta}{3 t}\left(k_{1}^{2}-k_{2}^{2}\right)\right]^{2}
$$

The first order derivative method is used to solve the formula.

$$
\frac{\partial \pi_{2}^{B}}{\partial k_{2}}=\frac{2 \beta}{3} k_{2}\left[1+\frac{\beta}{3 t}\left(k_{1}^{2}-k_{2}^{2}\right)\right]
$$

Only when $k_{1}=k_{2}=0, \pi_{1}^{B}$ or $\pi_{2}^{B}$ have the best solution, that is $\frac{t}{2}$. This has become a win-win equilibrium point of two high tech enterprises in different countries.

\section{CONCLUSION}

Through the Hotelling model, we get the equilibrium solution of product pricing, that is, the high tech industry trading country can achieve a win-win situation in the same price. Otherwise, if a country's price is lower than the equilibrium price, it may be bring adverse effects to other companies, and even trigger trade disputes. Therefore, countries should establish a high tech industry cooperation organization, in order to reach a consensus on product pricing and to reduce the various trade frictions. Therefore, countries should establish a high-tech industry cooperation organization, in order to reach a consensus on product pricing and to reduce the various trade frictions. At the same time, improving the corresponding international laws and regulations also has important practical significance.

\section{ACKNOWLEDGMENT}

The authors thank professor Zhao for her valued assistance and guidance. We can learn a lot of professional knowledge to improve personal ability under the guidance of the professor Zhao.

\section{REFERENCES}

[1] Yu Chunjiao. Analysis on the economic growth effect of foreign trade of China's high tech products [J]. Journal of Inner Mongolia Finance and Economics College, 2011(05):41-48.(In Chinese)

[2] Yang Dong. Research on the factors of China's high tech products [D]. Ningbo University, 2009.I.S. Jacobs and C.P. Bean, "Fine particles, thin films and exchange anisotropy," in Magnetism, vol. III, G.T. Rado and H. Suhl, Eds. New York: Academic, 1963, pp. 271-350. (In Chinese)

[3] Porter, A. L., Newman, N. C., Roessner, J. D., Johnson, D. M. and Jin, X. Y. International High Tech Competitiveness: Does China Rank Number [J]. Technology Analysis \& Strategic Management, 2009, 21 (2): 173-193. R. Nicole, "Title of paper with only first word capitalized," J. Name Stand. Abbrev., in press.

[4] Yu Weisheng. Game theory and its application in economic management [M]. Beijing: Qinghua University Press, 2005. (In Chinese)

[5] Jia Xiuyan. Dynamic game analysis of high tech enterprise cluster information sharing [J]. Information Science, 2014, 32(5):64-68. (In Chinese)

[6] Shulin Liu, Yutian Li. The present situation and development strategy of high tech industry in Western China, J. Hubei Social Sciences. 2002(02):46-47. (In Chinese)

[7] Bloch, H. and Tang, S. The Effects of Exports, Technical Change and Markup on Total Factor Productivity Growth: Evidence from Singapore's Electronics Industry, J. Economic Letters. 2007(96):58-63. 